\title{
A randomized controlled trial of Bupropion on Nicotine Dependence and Positive and Negative symptoms amongst patients suffering from schizophrenia attending the out-patient department of a tertiary care centre
}

\author{
Smit J. Parmar ${ }^{1}$, Bhavesh B. Kathiriya ${ }^{2}$, Prakash I. Mehta ${ }^{3}$ \\ 1,23rd year Post Graduate student MD Psychiatry, GMERS Medical College and Civil Hospital, Sola, \\ Ahmedabad. \\ 3Profesor and Head, Department of Psychiatry, GMERS Medical College and Civil Hospital, Sola, \\ Ahmedabad. \\ Corresponding author: Bhavesh Kathiriya \\ Email - bhaveshkathiriya50425042@gmail.com
}

\begin{abstract}
Background: Smoking prevalence among individuals with schizophrenia is estimated to be from $64-79 \%$. Nicotine dependence is associated with public stress and health issues. It may diminish the therapeutic efficacy and the bioavailability of the psychopharmacological agents in-vivo. Bupropion increases smoking abstinence rates in smokers with schizophrenia, without jeopardizing their mental state. The study aimed to document the effect of Bupropion, on nicotine dependence amongst schizophrenia patients, and on positive and negative symptoms of schizophrenia.

Method: Total 39 patients were included in the study, group A (Case) $(n=18)$ was given Tablet Bupropion $(150 \mathrm{mg})$ in addition to ongoing treatment. Group B (Control) $(\mathrm{n}=21)$ was given treatment for schizophrenia as usual. Nicotine consumption was evaluated by self-reported consumption of nicotine, and Positive and Negative symptoms scale (PANSS) ${ }^{[4]}$ was taken at first visit and at follow up after 4 weeks.

Result: There was a $70.9 \%$ reduction in nicotine consumption in Group A $(0.86 \%$ in Group B) which was significant $(p$ - value $=0.000003)$. The result was not significant for positive symptom scale $(p$-value $=0.06)$, general psychopathology scale had significant reduction in score. ( $p$ value $=0.00021$ ) as evaluated by paired $t$ test. Reduction in negative symptom scale was present but could be secondary to sampling bias. ( $p$ value $=0.00108$ ).

Conclusion: Bupropion is effective in reducing consumption of nicotine as compared to when no active intervention is done for the same and it does not worsen nor improves any positive symptoms in the patient but can bring improvement in the general psychopathology symptoms of the schizophrenic patients when they are on maintenance treatment.
\end{abstract}

Key words: schizophrenia, positive symptoms, negative symptoms, Bupropion.

(Paper received $-10^{\text {th }}$ February 2020, Peer review completed $-20^{\text {th }}$ February 2020)

(Accepted $-24^{\text {th }}$ February 2020)

\section{INTRODUCTION}

According to Global Adult Tobacco survey conducted in 2016-17, 42.4\% of men, 14.2\% of women and $28.6 \%$ (266.8 million) of all adults currently use tobacco (smoked and/or smokeless tobacco). Prevalence of consumption of tobacco (smoking/smokeless) is $25.1 \%$ [1]. Nicotine dependence has progressively become a foremost community health interest in both developed and developing nations due to the economic burden and health-related problem. Smoking is significantly higher among patients with schizophrenia in comparison to the general population. Individuals with schizophrenia smoke more heavily than the general 
population and this contributes to their higher morbidity and mortality from smoking-related illnesses. People with schizophrenia smoke about 5.6 times as much as people without the disease [2]. The rate of smoking prevalence among individuals with schizophrenia is estimated to be from 64 to $79 \%$ [3]. Mortality from smoking-related diseases, such as pulmonary and cardiovascular diseases, is 2 to 6 times higher in patients with schizophrenia than in age-matched nonpsychiatric controls.

Among patients with schizophrenia, smoking brings major challenges to its management. Nicotine may diminish the therapeutic efficacy and bioavailability of the psychopharmacological agents in-vivo. Smoking, but not nicotine, induces hepatic microsomal enzyme activity, particularly that of cytochrome P-450 1A2 (CYP1A2), and thus reduces blood levels of many antipsychotic medications, particularly clozapine and olanzapine. Converging evidence indicates that a majority of smokers with schizophrenia want to quit smoking, and that available pharmacotherapeutic smoking cessation aids are well tolerated by this population of smokers and are effective, but they are unable to do so because of increased vulnerability [3]. This factor is a major but treatable cause of morbidity and mortality in this patient population. Nevertheless, health professionals make relatively little effort to discourage people from smoking or to give it up altogether, as the success rate for it are very less in schizophrenia patients with nicotine use. Indian study mostly has been on use of nicotine substances in schizophrenia patients but very few studies are there on management of these patients. Nicotine dependence and negative symptoms being very resistant to treatment are not effectively handled by psychiatrists in current practice [4-6].

Bupropion (BUP) is a weak catecholamine reuptake inhibitor [7], which also is a potent non-competitive ion channel site antagonist at the nicotinic acetylcholine receptor (nAChR) [8]. The sustained-release (SR) formulation of BUP was approved for smoking cessation in the United States in 1997, based on two pivotal studies [11-12]. Bupropion increases smoking abstinence rates in smokers with schizophrenia, without jeopardizing their mental state [5]. Bupropion appears to have efficacy versus placebo and does not exacerbate psychiatric symptoms. Maintenance pharmacotherapy may reduce relapse and improve sustained abstinence rates.

\section{METHODOLOGY}

\section{Inclusion criteria}

Participants in this study were patients of all age and sex coming to psychiatry department for treatment of schizophrenia as diagnosed by consultant. They should be on stable doses of their antipsychotic drugs and those patients should have a habit of consuming nicotine in any form, i.e., smoking cigarette or bidi or chewing or snuffing tobacco products. Informed consent was taken of patients who wished to participate in this study.

\section{Exclusion Criteria}

Patients with acute physical illness (General condition poor), or, with acute psychotic episode with significant behavioural problem or hospitalization, or, those having seizure disorder or increased risk of seizure disorder and those who did not wish to participate in the study were not included in the study.

\section{Sampling technique}

Permission from ethics committee was taken. Patients were randomized into two groups. Group A was given Tablet Bupropion in fixed dose of $150 \mathrm{mg}$ in addition to ongoing treatment for schizophrenia. Group $\mathrm{B}$ was given treatment for schizophrenia as usual. No additional psychological counselling/behavioural intervention for nicotine dependence was done in both group for the period of study. Collection of sociodemographic data and Positive and Negative symptoms scale (PANSS) [6] was given to them for assessment of schizophrenia at first visit (beginning of the study) and at follow up visit after 4 weeks. Amount of consumption of nicotine of the participants was evaluated of the patient by self-reported reduction of consumption of nicotine, at first visit and at follow up after 4 weeks. The average nicotine in 1 bidi was taken as $26.9 \mathrm{mg}$, and Nicotine concentration in chewing tobacco was taken as $3.4 \mathrm{mg} / \mathrm{gm}$. A packet of Tobacco product is approximately $5 \mathrm{gm}$, so one packet of chewing tobacco was roughly considered as $17 \mathrm{mg}$ of nicotine [7]. 


\section{STATISTICAL ANALYSIS}

The data was entered into an excel sheet, master chart was prepared. Chi square test, chi square test with Yates correction, Mann-Whitney $U$ test and t-test was used to find statistical significance in this study wherever whichever was applicable.

\section{RESULTS}

Total 39 patients were included in the study and the patients enrolling in the study were randomly divided into two groups Group A (Case) had 18 patients and Group B (Control) had 21 patients. Table 1 depicts the socio demographic data of the two groups. The $\mathrm{P}$ values were obtained using Mann-Whitney U test for age and chi square test with yates correction was used for other parameters. There was no statistically significant difference in the two groups regarding socio demographic data collected as shown in the table, with the difference being significant at $\mathrm{p}<0.05 .11(28.20 \%)$ out of the total number of patients in this study started nicotine after the onset of illness and the rest $(71.80 \%)$ had the habit even before the illness began. The average duration of illness and the duration of consumption of nicotine is almost same in both groups (around 11 and 15 respectively).

Table 1: Socio-demographic data

\begin{tabular}{|c|c|c|c|c|c|}
\hline \multicolumn{2}{|c|}{ Socio Demographic Data } & $\begin{array}{l}\text { Group A } \\
(\mathrm{n}=18)\end{array}$ & $\begin{array}{l}\text { Group B } \\
(\mathrm{n}=21)\end{array}$ & $\begin{array}{l}\text { Total } \\
(\mathrm{n}=39)\end{array}$ & $\mathrm{P}$ value \\
\hline \multicolumn{2}{|c|}{ Age (mean in years) } & 41.8 & 45.8 & 43.39 & 0.257 \\
\hline \multirow[t]{2}{*}{ Sex ratio } & Male & 13 & 14 & 27 & \multirow[t]{2}{*}{0.708} \\
\hline & Female & 5 & 7 & 12 & \\
\hline \multirow[t]{2}{*}{ Residence } & Urban & 12 & 13 & 25 & \multirow[t]{2}{*}{0.979} \\
\hline & Rural & 6 & 8 & 14 & \\
\hline \multirow[t]{2}{*}{ Education } & Educated & 16 & 20 & 36 & \multirow[t]{2}{*}{0.889} \\
\hline & Uneducated & 2 & 1 & 3 & \\
\hline \multirow[t]{2}{*}{ Employment } & Employed & 7 & 10 & 17 & \multirow[t]{2}{*}{0.823} \\
\hline & Unemployed & 11 & 11 & 22 & \\
\hline \multirow{4}{*}{$\begin{array}{l}\text { Socio-economic } \\
\text { status }\end{array}$} & lower class & 2 & 4 & 6 & \multirow[t]{4}{*}{0.22} \\
\hline & lower middle class & 3 & 7 & 10 & \\
\hline & middle class & 9 & 4 & 13 & \\
\hline & $\begin{array}{l}\text { Upper middle + upper } \\
\text { class }\end{array}$ & 4 & 6 & 10 & \\
\hline
\end{tabular}

Table2: Nicotine Reduction in the groups

\begin{tabular}{|l|l|l|l|}
\hline \multirow{2}{*}{} & \multicolumn{2}{|l|}{$\begin{array}{l}\text { Average consumption of nicotine } \\
\text { (in mg) }\end{array}$} & $\begin{array}{l}\text { Percentage reduction in average } \\
\text { consumption of nicotine }\end{array}$ \\
\cline { 2 - 3 } & First Visit & $\begin{array}{l}\text { Follow Up } \\
\text { Visit }\end{array}$ & \\
\hline Group A & 164.51 & 47.86 & $70.90 \%$ \\
\hline Group B & 118.07 & 117.05 & $0.86 \%$ \\
\hline
\end{tabular}

As depicted in table 2, there was $70.9 \%$ reduction in nicotine consumption in group A compared to $0.86 \%$ reduction in group B. Chi square test with Yates correction was used to find the significance in reduction of nicotine consumption in Group A compared to Group B. 
Table 3: Reduction in nicotine consumption in both groups

\begin{tabular}{|l|l|l|l|}
\hline \multirow{2}{*}{} & \multicolumn{2}{|l|}{$\begin{array}{l}\text { Reduction in consumption of nicotine in } \\
\text { schizophrenic patients }\end{array}$} & \multirow{2}{*}{ Marginal row totals } \\
\cline { 2 - 4 } & Reduction present & No reduction & \\
\hline Group A & $17(9.23)[6.54]$ & $1(8.77)[6.88]$ & 18 \\
\hline Group B & $3(10.77)[5.6]$ & $18(10.23)[5.9]$ & 21 \\
\hline Marginal column totals & 20 & 19 & 39 (grand total) \\
\hline
\end{tabular}

As derived from table 3 , the chi square statistic with yates correction is 21.822 . the p-value is 0.000003 . the result is significant at $p<0.05$. This implies that there is significant reduction in consumption of nicotine in schizophrenic patients who are given bupropion. The odd's ratio was 102. Which signifies that chance of reduction in nicotine consumption in schizophrenic patients when Bupropion is given to the patients is 102 times more than when no intervention is done in any form for the same. This value cannot be considered accurate due to low sample size.

Table 4: PANSS scores across both groups

\begin{tabular}{|l|l|l|l|}
\hline & Group A & Group B & p value \\
\hline Positive Score & 13.39 & 11.76 & 0.24 \\
\hline Negative Score & 22.61 & 18.43 & 0.036 \\
\hline Composite score & -9.78 & -6.67 & 0.074 \\
\hline General Psychopathology score & 33 & 28.57 & 0.085 \\
\hline
\end{tabular}

There was statistically significant difference in scores of negative symptom scale of PANSS in group A and group B. this indicates that there was a sampling bias in this study, such that the negative symptom score of both the groups had statistically significant difference in their scores at the beginning of the study. The difference in the other scores (positive, composite and general psychopathology scale) were not statistically significant.

Table 5- Change in mean scores of PANSS on first and follow up visit after 1-month in group A and group

\begin{tabular}{|l|l|l|l|l|l|}
\hline & & $\begin{array}{l}\text { Positive } \\
\text { Score }\end{array}$ & $\begin{array}{l}\text { Negative } \\
\text { score }\end{array}$ & $\begin{array}{l}\text { Composite } \\
\text { score }\end{array}$ & $\begin{array}{l}\text { General } \\
\text { Psychopathology score }\end{array}$ \\
\hline \multirow{4}{*}{ Group A } & First visit & 13.39 & 22.61 & -9.78 & 33 \\
\cline { 2 - 6 } & Follow Up Visit & 12.28 & 19.78 & -7.94 & 26.72 \\
\cline { 2 - 6 } & P value & 0.06 & 0.00108 & 0.00579 & 0.00021 \\
\hline \multirow{3}{*}{ Group B } & First visit & 11.76 & 18.43 & -6.67 & 28.57 \\
\cline { 2 - 6 } & Follow Up Visit & 11.52 & 18.23 & -6.71 & 28.14 \\
\cline { 2 - 6 } & P value & 0.22 & 0.213 & 0.394 & 0.179 \\
\hline
\end{tabular}

There was no significant reduction of PANSS scores in Group B after a follow up of 1 month. In group A there was no significant score change in positive score with the use of bupropion at $150 \mathrm{mg}$ dose after a duration of a month $(\mathrm{p}=0.06)$. There is a change in negative symptoms $(\mathrm{p}=0.00108)$, composite scale $(p=0.00579)$ and general psychopathology scale $(p=0.00021)$ with the use of bupropion at $150 \mathrm{mg}$ dose within a duration of 1 month. And the change is statistically significant. 


\section{DISCUSSION}

In this study both the groups had patients of around the same age group $(\mathrm{p}=0.26)$, had same average duration of illness and duration of consumption of nicotine. There were no significant differences in the two groups in sex ratio $(p=0.708)$, education $(p=0.89)$, occupation $(p=0.58)$, and socio-economic status $(p=0.22)$. There was a significant reduction of nicotine consumption with use of bupropion at a dose of $150 \mathrm{mg}$ at the end of 1 month in schizophrenic patients as compared to control group (p-value 0.000003). Bupropion is a weak inhibitor of dopamine and noradrenaline reuptake, and has also been shown to antagonise nicotinic acetylcholine receptor function. the principal mode of bupropion action is upon the withdrawal symptoms following smoking cessation; during withdrawal, bupropion may attenuate symptoms by mimicking nicotinic effects on dopamine and noradrenaline; its ability to antagonize nicotinic receptors may prevent relapse by attenuating the reinforcing properties of nicotine, but probably cannot acutely reduce smoking [13]. There was no improvement nor worsening in the positive symptoms of the patients which is consistent with other study [10]. Although there was improvement in negative symptoms with the use of bupropion in this study, there was a sampling bias in this result as the negative scores of both the groups at the beginning of the study had significant difference. This sampling bias could be present due to small sample size of this study and thereby can be reduced by increasing the sample size. In other studies, there has been an improvement in negative score findings are inconclusive.

It seems that the agents that induce dopamine release and/or delay dopamine reuptake in the central nervous system can promise to use in apathy. The preclinical and clinical researches have been demonstrated that bupropion acts via dual inhibition of dopamine reuptake. Therefore, this inhibitory effect may be associated with a unique clinical profile for improving negative symptoms in schizophrenia. Besides, because bupropion is a selective norepinephrine and dopamine reuptake inhibitor that has no effect on serotonergic system, common observable side effects which related to other antidepressants, such as weight gain, sexual dysfunction or sedation are not associated with bupropion use and therefore this drug can be superior to other agents for preventing negative symptoms. This hypothesis could hold true but the result regarding the negative symptoms in this study had a sampling bias, and the results from other studies are also varying.

There was improvement in the general psychopathology score which includes depression, anxiety, somatic complaints etc. This finding could not be corroborated with other studies as the other studies used Scales for the Assessment of Negative Symptoms (SANS) and Scale for Assessment of Positive Symptoms (SAPS) scale which does not have this score. This result could be probably as bupropion improves depression and anxiety so the patients having depression along with schizophrenia might have improved due to it.

\section{Limitations}

1. Small sample size

2. No blinding is used in this study

3. Short duration for follow up and only one follow up taken in this study

4. Fixed dose of bupropion

5. Self-reported reduction of tobacco consumption, no biochemical tests to confirm the level of nicotine in the body, no scale to assess the severity of nicotine consumption.

6. No placebo was used in the control group.

\section{CONCLUSION}

This study concludes that Bupropion is effective in reducing consumption of nicotine in patients who are on maintenance treatment for schizophrenia as compared to when no active intervention is done for the same. It does not worsen nor improves any positive symptoms in the patient but can bring improvement general psychopathology symptoms of the schizophrenic patient. Although there was improvement in negative symptoms in this study, the result cannot be conclusive as there was a sampling bias. 


\section{REFERENCES}

1. Global Adult Tobacco Survey FACT SHEET INDIA 2016-17.

2. Muller DP, de Haan L. Smoking cessation and schizophrenia. Tijdschrift voor Psychiatrie 2017;59(5):297-301.

3. Cather C, Pachas G, Cieslak K, Evins A. Achieving Smoking Cessation in Individuals with Schizophrenia: Special Considerations. CNS Drugs 2017;31(6):471-81.

4. Theng Y, Wahab S, Wahab N, Sidi H, Das S. Schizophrenia and Nicotine Dependence: What Psychopharmacological Treatment Options are Available for the Duo Perturbationes?. Curr Drug Targets 2018;20(2):173-81.

5. Tsoi D, Porwal M, Webster A. Interventions for smoking cessation and reduction in individuals with schizophrenia. Cochr Database Syst Rev 2013;(2):CD007253.

6. Kay S, Fiszbein A, Opler L. The Positive and Negative Syndrome Scale (PANSS) for Schizophrenia. Schizophr Bull 1987;13(2):261-76.

7. Reddy S, Shaik Hyder Ali K. Estimation of nicotine content in popular Indian brands of smoking and chewing tobacco products. Indian J Dent Res 2008;19(2):88-95.

8. Sagud M, Ćusa B, Jakšić N, Mihaljevic Peles A, Kuzman M, Pivac N. Smoking in Schizophrenia: an updated review. Psychiatr Danub 2018;30(5):288-94.

9. Yassini M, Shariat N, Nadi M, Amini F, Vafaee M. The effects of bupropion on negative symptoms in schizophrenia. Iran J Pharmaceut Res 2014;13(4):1227-33.

10. Rezaee OSM, Akbarpour F. A placebo-controlled trial of bupropion for improving the positive and negative symptoms of schizophrenia Int J Collab Res Int Med Pub Health 2012;4:1223-30.

11. Ferry L, Burchette R. Efficacy of bupropion for smoking cessation in non-depressed smokers. J Addict Dis 1994;13:249-55.

12. Hurt R, Sachs D, Glover E, Offord K, Johnston J, Dale L, Khayrallah M, Schroeder D, Glover P, Sullivan C, Croghan I, Sullivan P. A comparison of sustained-release bupropion and placebo for smoking cessation. New Engl J Med 1997;337:1195-202.

13. Warner C, Shoaib M. How does bupropion work as a smoking cessation aid?. Addict Biol 2005;10(3):219-31.

$* * * * * * * * * * * * * * * * * * * * * * * * * * * * * * *$
Acknowledgements - Nil
Conflict of Interest - Nil
Funding - Nil

